Check for updates

London, UK

Cite this as: BMJ 2020;371:m4430 http://dx.doi.org/10.1136/bmj.m4430 Published: 12 November 2020

\section{Covid-19: Governments should demand transparency on vaccine deals, says MSF}

Shaun Griffin

Médecins Sans Frontières (MSF) has called on governments to demand transparency from pharmaceutical companies on covid-19 vaccine licensing deals, costs, trials, and data, as a condition of funding.

Developments in covid-19 vaccines are advancing rapidly, with interim results from US Pfizer ${ }^{1}$ and Russia's Sputnik vaccine trials announced earlier this week. According to MSF, the UK government has contributed $€ 84 \mathrm{~m}\left(€_{94 \mathrm{~m}}\right.$; $\left.\$ 111 \mathrm{~m}\right)$ to support the development of AstraZeneca’s covid-19 vaccine, early results from which are expected imminently.

But the terms of the deal struck between AstraZeneca and UK government, or those of the four other deals made with other vaccine companies-from whom collectively it has pre-ordered $350 \mathrm{~m}$ doses $^{2}-$ have not been made public. The US has invested more than $\$ 12 b n$ in six front running covid-19 vaccines.

AstraZeneca has stated it will not profit from the vaccine during the pandemic. But in an agreement with Brazilian public research body Fiocruz seen by the Financial Times ${ }^{3}$ AstraZeneca defines the pandemic period as ending on 1 July 2021.

MSF said that this means that AstraZeneca "could charge governments and other purchasers, including the NHS, high prices for a vaccine that was predominantly funded by the public."

The fact that Fiocruz published its licence agreement with AstraZeneca should encourage other governments to follow suit and move towards more transparency, according to MSF. "Public scrutiny of the terms of these deals is critical to ensure equitable and affordable access," it said.

Kate Elder, senior vaccines policy advisor at MSF, said, “As long as we don't know what's in these deals, pharma will continue to hold the power to decide who gets access when, and at what price. Without decisive action from governments demanding more transparency from companies, equitable access to covid-19 vaccines is in jeopardy. The public has the right to know. There is no place for secrets during a pandemic, there is too much at stake."

Responding to a request for comment, the UK's Department for Business, Energy, and Industrial Strategy said, "Commercial confidentiality means we cannot release any information on agreements while any commercial negotiations between the government and vaccine manufacturers are ongoing. We aim to publish details regarding these contracts as soon as we can do so.

"The UK is also working closely with international organisations to ensure the UK is leading alongside other countries to ensure equal access to successful vaccines.”

AstraZeneca, which is developing the vaccine in collaboration with Oxford University, did not respond to requests for a comment.

Mahase E. Covid-19: Vaccine candidate may be more than 90\% effective, interim results indicate. BM/2020;371:m4347. doi: 10.1136/bmj.m4347 pmid: 33168562 Torjesen I. Covid-19: Pre-purchasing vaccine-sensible or selfish?BMJ 2020;370:m3226. doi: 10.1136/bmj.m3226 pmid: 32816716

AstraZeneca vaccine document shows limit of no-profit pledge. Financial Times. 7 October 2020. www.ft.com/content/c474f9e1-8807-4e57-9c79-6f4af145b686. 